\title{
Género y melodrama en la nota roja: el caso de María Teresa de Landa (México, 1929)
}

Eleatriz García-Blanco*

https://orcid.org/0000-0002-1014-0133

Recibido: 06 de abril de 2020 • Aceptado: 21 de agosto de 2020

\section{Resumen}

En este artículo se analizan, desde una perspectiva historiográfica, las notas publicadas en tres periódicos mexicanos de 1929 (El Nacional Revolucionario, El Universal y Excélsior) en torno al proceso judicial de María Teresa de Landa, quien confesó haber asesinado a su pareja sentimental. El objetivo es reflexionar sobre el melodrama como estrategia narrativa de la violencia y los entramados de significados en torno al género en la llamada nota roja periodística.

Palabras clave: Derecho a la justicia, violencia, crimen, México-Historia.

* Doctorante en Historiografía por la Universidad Autónoma Metropolitana de México. Maestra en Historiografía por la Universidad Autónoma Metropolitana de México, licenciada en Etnología por la Escuela Nacional de Antropología e Historia de México. Correo: a12113805200@azc.uam.mx 


\title{
Gender and Melodrama in Red Top Press: The Case of María Teresa de Landa (Mexico, 1929)
}

\begin{abstract}
In this article, the notes published in three Mexican newspapers from 1929 (El Nacional Revolucionario, El Universal y Excélsior) are analyzed from a historiographical perspective surrounding the judicial process of María Teresa de Landa, who confessed to having murdered her significant other. The objective is to reflect on melodrama as a strategic narrative of violence and fabric of meaning regarding gender in the so-called journalistic red top.
\end{abstract}

Key words: Right to justice, violence, crime, Mexican-history.

Genre et mélodrame dans la presse à sensation: le cas de María Teresa de Landa au Mexique en 1929

\section{Résumé}

Cet article analyse, dans une perspective historiographique, les articles publiés dans trois journaux mexicains en 1929 (El Nacional Revolucionario, El Universal y Excélsior) sur la procédure judiciaire de María Teresa Landa qui a avoué l'assassinat de son compagnon. Le but est de réfléchir sur le mélodrame comme stratégie narrative de la violence et les significations entrelacées au tour du genre dans la presse à sensation.

Mots-clés: Droit à la justice, violence, crime, Mexique-histoire. 


\section{Introducción}

El 25 de agosto de 1929, en la Ciudad de México, María Teresa de Landa disparó contra el general Moisés Vidal, a quien consideraba su esposo, al descubrir que era bígamo. Fue un caso que recibió una gran atención en la sociedad mexicana, ya que el año anterior María Teresa había sido electa la primera Señorita México y había participado en un concurso internacional de belleza, mientras que la víctima era un general revolucionario.

María Teresa pasó así a ser parte del grupo de «matadoras de hombres», mujeres jóvenes, de clase media y con estudios que, a lo largo de la década de los veinte del siglo pasado, asesinaron a sus parejas sentimentales ${ }^{1}$. Estas mujeres contradecían las teorías de la escuela criminológica mexicana, que atribuían a la pobreza, la ignorancia y el alcoholismo la comisión de crímenes ${ }^{2}$.

El interés por el caso de María Teresa se ha mantenido a lo largo del tiempo y se ha mirado desde diferentes perspectivas. Así, Luis de la Barreda Solórzano consideró que la exoneración de María Teresa se debió a su belleza, por haber seducido a los jurados populares, carentes de conocimientos jurídicos y fácilmente influenciables ${ }^{3}$; por lo tanto, la sentencia no fue bien recibida entre los expertos jurídicos, pues la conducta de la procesada no encuadraba en ninguna de las causas de inculpabilidad previstas en el Código Penal. A este caso particular se le atribuye el final del jurado popular en México ${ }^{4}$. Lo cierto es que la discusión sobre un nuevo Código Penal que abolía la pena de muerte y suprimía el jurado popular en delitos de fuero común, se había desarrollado meses antes del juicio a María Teresa ${ }^{5}$, mientras que una de las mayores preocupaciones de su abogado defensor era que el juicio se desarrollase antes del 15 de diciembre de 1929, fecha de supresión del jurado popular6.

${ }^{1}$ Entre otras, Magdalena Jurado, Alicia Olvera, Nidia Camargo y Luz González. Gerardo Australia señala que los casos de auto viudas habían sido conocidos desde mediados del siglo XIX, pero a partir del siglo XX los periódicos tuvieron un papel decisivo al investigar y mostrar gráficamente los detalles relacionados con los crímenes. Gerardo Australia, «De Miss México a Viuda Negra: el crimen pasional de María Teresa de Landa en 1929», Relatos e Historias en México, n. ${ }^{\circ} 57$ (2013), 26-33. El fenómeno de las llamadas matadoras de hombres también se manifestó en Estados Unidos de América, donde la periodista Maurine Dallas Watkins escribió la obra de teatro Chicago como una forma de denunciar la corrupción de los jueces y establecer el concepto de criminal estrella, a partir de los casos de Belulah Annan y Belva Gaertner.

${ }^{2}$ Robert M. Buffington, Criminales y ciudadanos en el México moderno (México D.F.: Siglo XXI, 2001).

${ }^{3}$ Luis de la Barreda Solórzano, El jurado seducido. Las pasiones ante la justicia (México D.F .: Porrúa, 2005), 9-18.

${ }^{4}$ Luis de la Barreda Solórzano, «El embrujo de María Teresa», Etcétera, 1 de octubre de 2007, acceso el 20 de setiembre de 2020, https://www.etcetera.com.mx/revista/el-embrujode-maria-teresa/

5 Elisa Speckman Guerra, «Crónica de una muerte anunciada: la supresión del juicio por jurado en el Distrito Federal», en El mundo del Derecho II: instituciones, justicia y cultura jurídica (México: UNAM/IIJ/Escuela Libre de Derecho, 2017), 395-423.

${ }^{6}$ Algunas notas periodísticas sobre la supresión del Jurado Popular son anteriores al juicio de María Teresa: «Los jurados populares deberán ser suprimidos», Excélsior, 1 de agosto de 1929; «No habrá más jurados sino de escritores», Excélsior, 10 de agosto de 1929; «Van a suprimir el jurado y la pena de muerte», Excélsior, 22 de agosto de 1929; otras señalan que 
Más abundantes son los análisis y reflexiones basados en la prensa periódica, como el de Víctor Ronquillo, que señala la diferencia entre las notas publicadas en $E l$ Nacional Revolucionario y Excélsior, las que justifica por la antipatía o simpatía hacia la acusada, respectivamente ${ }^{7}$.

A su vez, Aurelio de los Reyes considera la forma en que las notas periodísticas de algunos casos de mujeres homicidas entrelazaban los conceptos del honor, el perfil de la figura materna, las expectativas de vida de las mujeres y la integración del núcleo familiar. Considera que cada una de estas historias refleja aspectos de la vida de las mujeres, como la lucha por sobrevivir durante el movimiento armado y sus secuelas, así como la venganza del honor. Agrega que el consumo y la aceptación de estas historias, reflejan los valores entendidos de la sociedad y la forma en que se van transformando. Desde su perspectiva, la sociedad mexicana intentaba rearticularse tras el impacto del movimiento revolucionario, refugiándose en la familia nuclear y los valores de la madre y el honor. Esto generaba un nuevo conservadurismo ante la creciente incorporación de las mujeres a la vida pública, los movimientos feministas y socialistas, como también una moral más permisiva que Estados Unidos de América exportaba por medio del cine ${ }^{8}$.

La mirada de Víctor Manuel Macías González se enfoca en la construcción narrativa, al considerar que la representación melodramática del caso de María Teresa ofrece un cuadro en el que ha quedado plasmado el imaginario colectivo del México de los años veinte. También señala que este incidente evidenciaba una lucha cultural en torno a la identidad nacional, las nuevas concepciones del género, el fenómeno de modernización y el proyecto nacional del gobierno posrevolucionario. Considera que, en el veredicto del jurado, se trasluce la forma en que la fama, la riqueza y los atributos físicos permitían la impunidad. Macías otorga una gran importancia a los concursos de belleza para moldear un espíritu de uniformidad, pertenencia y comunidad ${ }^{9}$.

el juicio de María Teresa fue de los últimos en comparecer ante un Jurado Popular: «María Teresa de Landa comparecerá en Jurado en la próxima semana», Excélsior, 9 de noviembre de 1929; «El escándalo del último jurado», El Universal, 3 de diciembre de 1929; «Los últimos jurados para esta semana», El Nacional Revolucionario, 10 de diciembre de 1929. La supresión del Jurado Popular en el Distrito Federal fue un hecho de gran relevancia en la historia jurídica mexicana; sin embargo, dada la extensión e intención de este artículo no es posible reseñarla aquí, pero las personas lectoras interesadas en tener mayor información sobre su relación con el proceso de María Teresa, pueden consultar: Eleatriz García Blanco, «En defensa de las ilusiones: representaciones de una mujer delincuente en la prensa mexicana posrevolucionaria» (tesis de Maestría, Universidad Autónoma Metropolitana, 2016), http://posgradocsh.azc.uam.mx:8080/es/Historiografia/Representaciones_mujer_delincuent $\mathrm{e}$

${ }^{7}$ Víctor Ronquillo, La nota roja. 1920-1929 (México D.F.: Grupo Editorial Siete, 1996).

8 Aurelio de los Reyes, Bajo el cielo de México 1920-1924 (México: Instituto de Investigaciones Estéticas/UNAM, 1993). Aurelio de los Reyes, «Crimen y castigo: la disfunción social en el México posrevolucionario», en Historia de la vida cotidiana en México en el siglo XX (México: El Colegio de México, 2005), 301-343.

${ }^{9}$ Víctor Manuel Macías González, «El caso de una beldad asesina: la construcción narrativa, los concursos de belleza y el mito nacional posrevolucionario (1921-1931)», Historia y Grafía, n. ${ }^{\circ} 13$ (1999), 113-154. 
Desde una perspectiva más literaria, Eduardo Rojas Rebolledo se centra en la construcción de los personajes de María Teresa y Moisés. Señala que el concurso internacional de belleza en el que participó María Teresa era visto como una prueba del ingreso del país a la modernidad ${ }^{10}$.

Por su parte, Gerardo Australia califica a la sociedad mexicana de esa época como machista, que exigía a las mujeres sumisión, lealtad y distancia hacia las ideas feministas, las cuales consideraba meras influencias extranjeras. Aun así, había mujeres como Frida Kahlo ${ }^{11}$, Dolores del Río ${ }^{12}$ y Lola Álvarez Bravo ${ }^{13}$ que rompían convencionalismos y prohibiciones, quienes influían en las nuevas generaciones de mexicanas. Australia agrega que los casos de auto viudas habían sido conocidos desde mediados del siglo XIX, pero a partir del siglo XX los periódicos tuvieron un papel decisivo al investigar y mostrar gráficamente los detalles relacionados con los crímenes $^{14}$.

Para Rebeca Monroy Nasr ${ }^{15}$, el análisis de las auto viudas de los primeros años posrevolucionarios contribuye a la construcción de una historia del género y reflexiona sobre las imágenes como un reencuentro visual con el pasado para analizar las transformaciones y representaciones de los cuerpos. La perspectiva de Monroy considera la construcción de nuevos sujetos y nuevas identidades en el proceso de la modernización del país.

La autora de este artículo concuerda con que el caso de María Teresa se ubica en el proceso de modernización del Estado mexicano, en el que los debates sobre el género, la familia y las relaciones amorosas corresponden a un nuevo régimen de discurso y a la construcción de nuevos sujetos y nuevas identidades. En ese sentido, se reconoce la importancia de la prensa escrita para posicionar en la esfera pública

${ }^{10}$ Eduardo Rojas Rebolledo, «María Teresa Landa», en El libro rojo. Continuación. 19281959 (México D. F.: Fondo de Cultura Económica, 2011), 38-53.

${ }^{11}$ Frida Kahlo (1907-1954), pintora y poetisa mexicana. En 1922 fue de las primeras mujeres en ingresar a la Escuela Nacional Preparatoria, donde tuvo una gran participación política. Tras un grave accidente en 1925, se dedicó a la pintura, logrando gran notoriedad. Su éxito en la pintura, su matrimonio con Diego Rivera (uno de los más famosos muralistas mexicanos), su bisexualidad y su militancia política de izquierda, la hacían una mujer poco convencional para la sociedad mexicana de esa época.

${ }^{12}$ María de los Dolores Asúnsolo y López-Negrete (1904-1983), conocida como Dolores del Río, era una joven perteneciente a la alta sociedad mexicana. En 1921 contrajo matrimonio con Pablo Martínez del Río, miembro de una de las familias más ricas del país. Sin embargo, en 1924, tuvieron una crisis económica, y en 1925 decidieron viajar a Hollywood para que Dolores actuara y Pablo escribiera guiones de cine. Dolores se convirtió en una gran estrella. En 1928 la pareja se divorció y Dolores continuó su carrera cinematográfica en Estados Unidos, México, España y Argentina.

${ }^{13}$ Dolores Concepción Martínez Anda (1907-1993), conocida como Lola Álvarez Bravo, fue una fotógrafa mexicana de gran importancia en las nuevas tendencias artísticas del México posrevolucionario.

${ }^{14}$ Gerardo Australia, «De Miss México a Viuda Negra: el crimen pasional de María Teresa de Landa en 1929».

${ }^{15}$ Rebeca Monroy Nasr, «Identidades perdidas: Miss México 1928», Anales del Instituto de Investigaciones Estéticas 36, n. ${ }^{\circ}$ 104, 2014, acceso: 20 de setiembre de 2020, http://www.analesiie.unam.mx/index.php/analesiie/article/view/2518/2496

ESPIGA' C(1) (1) (2) Año 20, N. 40: 140-157, julio - diciembre 2020 
los casos de las «matadoras de hombres» y los debates sobre el papel de las mujeres en el proyecto de nación que se intentaba consolidar.

Sin menoscabar el gran interés que desde lo jurídico tiene el caso de María Teresa, el interés de este artículo se centra en la representación que tres periódicos de circulación nacional construyeron de una mujer delincuente, esto desde una perspectiva de género ${ }^{16}$, en un momento de crisis del Estado mexicano, debido al asesinato de un presidente recién reelecto y al activismo político a favor del sufragio femenino.

Esto significa que la autora de este artículo asume las fuentes periodísticas un «tamiz que transmite o calla, informa, deforma, organiza y elabora en relación con unos parámetros variables» ${ }^{17}$; especialmente, en el caso de la prensa moderna, no se puede pasar por alto que el periódico es una mercancía y, a la vez, instrumento de poder en manos de grupos políticos, por lo que a mayor capacidad informativa, mayor perfeccionamiento de las técnicas y estrategias de manipulación del discurso (escrito e iconográfico), con el fin de convencer y orientar a las personas lectoras de manera más o menos disimulada ${ }^{18}$.

En ese sentido, la consulta de diversos periódicos sobre un mismo hecho permite, más que contrastar diferentes versiones, entender el proceso de construcción de los textos periódicos como problemas de interpretación de los hechos, no solo de los que explícitamente informan, sino también de aquellos elementos implícitos que inciden en la recepción de los textos. A diferencia de Ronquillo, se perciben las diferencias y similitudes entre los periódicos como elementos de un mismo proceso de construcción de individuos «generizados» ${ }^{19}$, y no solo como expresiones a favor o en contra de María Teresa. En ese sentido, se coincide con Monroy, en la importancia de este caso para la historia de género, cuyas diferencias son el uso de fuentes: las imágenes, en el caso de ella, y los textos periodísticos en el caso de quien escribe este artículo (lo cual no significa que sean complementarios, sino que las estrategias de análisis difieren).

Así, en este artículo se analiza las notas periodísticas del juicio de María Teresa de Landa del 25 de agosto al 15 de diciembre de 1929, publicados en tres diferentes periódicos, con el objetivo de reflexionar sobre el entramado de significados en torno al género, en la llamada nota roja periodística, la cual informa sobre los delitos que

\footnotetext{
${ }^{16}$ Reflexiones en torno a las noticias sobre delincuentes hombres y la homosexualidad vista como delito, contemporáneas al caso de María Teresa se pueden consultar en: García Blanco, «En defensa de las ilusiones: representaciones de una mujer delincuente en la prensa mexicana posrevolucionaria», 115-156.

17 Jacqueline Covo, «La prensa en la historiografía mexicana: problemas y perspectivas», Historia Mexicana, n. $^{\circ} 3$ (1993), 689.

${ }^{18}$ Covo, «La prensa en la historiografía mexicana: problemas y perspectivas», 691.

${ }^{19}$ Lo que implica considerar la cultura de género como la ha conceptualizado Elsa Muñiz: el complejo proceso de «generizar» a los individuos: desde la división sexual del trabajo que corresponde a una formación social y un momento determinados; el nivel relacional que permite abordar las interacciones entre los géneros y recrear las tensiones que se generan en la constante negociación de las normativas de género; y la elaboración simbólica, «en el sentido de entender a la cultura como un entramado de significaciones creador de representaciones individuales y colectivas». Elsa Muñiz, Cuerpo, representación y poder (México: UAM/Grupo Editorial Miguel Ángel Porrúa, 2002), 10.

ESPIGAd @(1) (2) Año 20, N. ${ }^{\circ} 40: 140-157$, julio - diciembre 2020 
se considera deben ser conocidos públicamente, así como sus procesos judiciales y el uso del melodrama como recurso narrativo.

\section{Tres periódicos mexicanos en tiempos de la Revolución}

Los textos analizados corresponden a tres periódicos diferentes de la Ciudad de México. El Universal y Excélsior se fundaron en 1916 y 1917, respectivamente, para dar a conocer los trabajos del Congreso Constituyente y los postulados de la Revolución mexicana. Ambos siguieron el modelo empresarial, que combinaba la información con la generación de ganancias por medio de la venta de espacios publicitarios. Los reporteros eran los encargados de investigar y redactar las notas, de manera anónima, la mayoría de las veces, pues la autoría se reconocía solo a algunos editorialistas o autores prestigiosos, aunque también abundaban los seudónimos.

En esos años se estableció una nueva relación entre gobierno y prensa: el gobierno contaba con aliados que le ayudaban a difundir su programa político y la prensa obtenía ganancias; así, el gobierno era uno de los principales compradores de publicidad y suscripciones. Sin embargo, los intereses comerciales de El Universal y Excélsior, los llevaron a centrarse en sectores específicos de público, transformando sus contenidos al gusto de las clases media y alta, con lo cual empezaron a tomar una actitud crítica hacia los gobiernos posrevolucionarios, que se ostentaban de base popular, por esto, constantemente eran llamados «enemigos de la Revolución», por el grupo gobernante ${ }^{20}$.

El Nacional Revolucionario surgió en mayo de 1929 como órgano informativo del recién creado Partido Nacional Revolucionario (PNR), para difundir sus actividades políticas, apoyar las campañas de sus candidatos y atacar a sus contrincantes. Desde entonces y hasta 1998, El Nacional Revolucionario se encargó de fijar la postura oficial de los gobiernos en turno ${ }^{21}$.

\section{María Teresa de Landa en el México de 1929}

De agosto a diciembre de 1929, mientras se realizaba el proceso de María Teresa, el Estado mexicano posrevolucionario aún se encontraba en construcción. Diversas facciones políticas estaban dispuestas a tomar las armas a la menor provocación. El presidente Álvaro Obregón ${ }^{22}$, recién reelecto en julio, había sido asesinado y las

${ }^{20}$ María del Carmen Ruiz Castañeda, «La prensa de la Revolución (1910-1917)», en El periodismo en México: 500 años de historia (México: Edamex/Club Primera Plana, 1998), 263-286; Arno Burkholder de la Rosa, «El periódico que llegó a la vida nacional. Los primeros años del diario Excélsior (1916-1932)», Historia Mexicana LVIII, n. ${ }^{4}$ (1999), 1389-1390.

${ }^{21} \ll 85^{\circ}$ aniversario de la fundación de El Nacional», Instituto Nacional de Estudios Históricos de las Revoluciones de México, acceso: 12 de junio de 2020, http://www.inehrm.gob.mx/es/inehrm/85_Aniversario_de_la_fundacion_de_el_Nacional

22 Álvaro Obregón (1880-1928), militar de la facción carrancista durante la Revolución de 1917, fue presidente de México durante el periodo 1920-1924. El 17 de julio de 1928, tras ser reelecto presidente para el periodo 1928-1934, fue asesinado en un restaurante de la Ciudad de México.

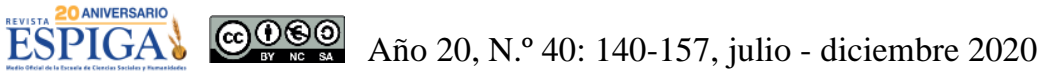


sospechas apuntaban al presidente en funciones, Plutarco Elías Calles, quien, para apartar de sí las dudas, convocó a elecciones extraordinarias, en las que no se presentó como candidato, pero fue importante protagonista en la fundación del PNR, cuyo nombre cambió posteriormente a Partido de la Revolución Mexicana y después a Partido Revolucionario Institucional, del que surgieron todos los presidentes mexicanos desde 1929 hasta el 2000.

Así, el caso de María Teresa compartió espacio en los periódicos con las campañas presidenciales y, también, con los movimientos políticos y sociales que llamaban la atención por la participación de mujeres: desde quienes exigían su derecho a elegir libremente a su pareja o separarse sin tener que recurrir al arbitrio del Estado, el derecho al control natal, a la igualdad con los hombres y a ocupar puestos de elección popular; a las partidarias de José Vasconcelos, candidato opositor al PNR; a las agrupadas en organizaciones propias para establecer sus intereses especificos y estrategias, como las de participar como funcionarias de casilla en las elecciones, aun cuando no tuvieran el derecho a votar; y hasta las que se afiliaban al PNR con la intención de lograr algún día el reconocimiento de sus derechos políticos.

Probablemente no todas las mujeres jóvenes de la ciudad de México tenían conciencia política de las demandas feministas, pero un gran número se sentían atraídas por lo que los medios propagaban, especialmente el cine: las modas europeas y estadounidenses en ropa y maquillaje; las actitudes desenfadadas y libres de los personajes femeninos; los romances apasionados ${ }^{23}$. Eran los tiempos modernos y las mujeres mexicanas aspiraban a ser parte de esos nuevos estilos de vida y los adoptaban y adaptaban a su cotidianeidad.

\section{Representaciones de una mujer delincuente}

Queda la duda de si María Teresa de Landa realmente mató al general Moisés Vidal. Ella confesó el homicidio, pero no hubo más pruebas o testimonios convincentes, mientras que los diferentes relatos periodísticos construidos sobre crimen, se enfocaron más al tipo de mujer que era María Teresa, que en los hechos ocurridos.

Así, los datos que hay de ella, como individuo, son los que se utilizan para ubicarla en un tipo específico de mujer. Para El Nacional Revolucionario, es la amoral concursante en traje de baño; para El Universal, la mujer presa de su naturaleza psicológica, y para Excélsior, la bella joven de familia honorable ante un implacable fiscal. Cada una de estas caracterizaciones corresponde a los intereses políticos y económicos de cada informativo.

23 En las sociedades premodernas, la institución matrimonial servía para regular el intercambio de riqueza. El matrimonio ideal era aquel en el que las fortunas de ambas partes eran equitativas y permitía conservar o mejorar la posición de las familias. El amor romántico surgió como una rebeldía que exaltaba al individuo y su elección amorosa por sobre los intereses del grupo familiar. Priorizando los sentimientos, la irracionalidad, el altruismo y la indiferencia hacia la riqueza, el amor romántico es la construcción cultural de las modernas sociedades capitalistas que impulsan la individualización y establecen la división entre lo privado (representado como el lugar de los sentimientos y afectos en el que se realiza la reproducción social que no se reconoce como actividad económica) y lo público (el espacio de producción y circulación de la riqueza). Eva Illouz, El consumo de la utopía romántica: el amor y las contradicciones culturales del capitalismo (Buenos Aires/Madrid: Katz, 2009), 25-34.

ESPIGA] @(1)(9)(2) Año 20, N. 40: 140-157, julio - diciembre 2020 
Para El Nacional Revolucionario, el crimen era consecuencia de la falta de moral ${ }^{24}$. Este periódico evitaba la nota roja por considerarla una apología del crimen, pero la cobertura del caso de María Teresa le permitió moralizar respecto a las mujeres, tomando como pretexto a una homicida. Al hacerlo, difundía el modelo de mujer mexicana que el Estado mexicano quería establecer.

Por su parte, El Universal prefirió adoptar una perspectiva «científica», basada en la psicología como ciencia forense, para mantener una postura neutra que le permitía mantener una cierta distancia con la perspectiva gubernamental, pero no lo suficientemente distante como para perturbar el delicado equilibrio entre mantener sus propias ideas para conservar su público y recibir el pago por la propaganda del Estado para mantener su solvencia económica y evadir la censura.

Para Excélsior, el caso de María Teresa implicaba un enfrentamiento con el grupo en el poder al defender a la presunta homicida. Identificó a María Teresa como miembro de una familia honorable, enfrentada a un Estado representado por autoridades judiciales parcializadas.

El interés por generar una representación específica de acuerdo con los intereses de cada rotativo es evidente en la selección de la información del juicio que cada uno imprimió. El Nacional Revolucionario dedicó casi todos sus textos a la actuación y argumentación del Presidente de Debates y el Fiscal, además pretextó la falta de espacio para resumir lo más posible la intervención del abogado defensor. $E l$ Universal cubrió de una manera más equilibrada a ambas partes. Y Excélsior dio más espacio que los otros dos periódicos a los argumentos de la defensa.

Sin embargo, hay un punto común en las tres representaciones: el melodrama, la narración que acentúa los aspectos patéticos y sentimentales. Si bien el melodrama tiene como antecedentes la tragedia griega y su catarsis -que permite purificar las sensaciones de iniquidad y pecado al identificarse con imágenes ennoblecidas-, así como la religión judeocristiana -que considera la existencia humana como una serie de suplicios en los que anteponer los intereses comunitarios a los propios permite ganar la dicha extraterrenal-; es un factor de modernidad en la medida en que se concreta en el carácter y temperamento individual. Es el individuo, propietario de la dignidad, no la colectividad, quien vence el pecado o el infortunio en un mundo $\operatorname{adverso}^{25}$.

La apelación que hace el melodrama a las emociones y sentimientos del público permite la identificación con los personajes, el reconocimiento de las virtudes a las que se aspira, la sublimación de la experiencia propia y la catarsis que remite a una fatalidad que se acepta, pero no se transforma.

Donde mejor se utiliza el melodrama es en la narración de la violencia, tal y como se presenta en la nota roja, con epítetos truculentos y un lenguaje exaltado. Entonces, «la víctima real o posible de la violencia se traduce a sí misma sus vivencias y miedos

\footnotetext{
${ }^{24}$ «Los padres son culpables de la degeneración», El Nacional Revolucionario, 9 de agosto de 1929.

${ }^{25}$ Carlos Monsiváis, «El melodrama: "No te vayas mi amor, que es inmoral llorar a solas"», en Narraciones anacrónicas de la modernidad: melodrama e intermedialidad en América Latina (Santiago de Chile: Editorial Cuarto Propio, 2002), 105-108. 
como episodios melodramáticos, no solo por no disponer de otra escuela narrativa, sino porque al hacerlo revive situaciones límite con un idioma que así mismo se neutraliza. Sin tal estrategia, la violencia repercutiría aún más» ${ }^{26}$. La narración melodramática de la violencia se convierte en la mediación entre la experiencia real y su enunciación oral y escrita. La violencia real es transformada en un lenguaje de sufrimiento y resignación, en un mundo representado en principio como adverso, e «impulsa la metamorfosis de lo vivido con temor y angustia en la representación teatral» ${ }^{27}$.

Pero ocurre que «la voluntad de escenificación es tan grande que oculta el sentido de lo representado» ${ }^{28}$; precisamente, lo que ejemplifican las narraciones del caso de María Teresa de Landa: la escenificación y la representación que cada periódico construye acaba por anular a la verdadera persona en aras del interés político de los grupos que dirigen cada periódico. Se establece entonces la función didáctica del melodrama en tanto enseña a pactar sentimentalmente con la realidad. El melodrama, incluso, llega a ser un chantaje sentimental cuando se apela a los nobles sentimientos del público para confirmar y aceptar el sentido y significado que se atribuye a un hecho $^{29}$.

Es importante tener en cuenta que, en la prensa mexicana del siglo $\mathrm{XX}$, los datos verídicos de la violencia al narrarse como melodramas, aterran, inhiben, abruman y anulan la voluntad de entender las dimensiones de la delincuencia y las respuestas eficaces $^{30}$. Es decir, las representaciones que construyó (y en algunos casos, sigue construyendo) la prensa periódica en torno a la violencia, recurren a estas estrategias melodramáticas que intensifican las sensaciones de inseguridad con una gran cantidad de datos, pero sin proporcionar el análisis necesario que permita desarrollar respuestas eficaces ante la violencia experimentada y nulifica las posibilidades de solidaridad.

Esto ocurre porque el melodrama tiene un uso político. Al aterrorizar e inmovilizar a la población cuando se identifica con las víctimas o las situaciones cotidianas en las que se puede desarrollar la violencia, así como los discursos que consideran la delincuencia como un hecho inevitable de los espacios urbanos y de la desigualdad social, las personas acaban por aceptar el dominio de grupos de poder que ofrecen controlar la delincuencia a través del uso legítimo de la fuerza, aun cuando esto signifique renunciar a derechos y libertades individuales.

\section{El género a juicio}

El melodrama en las notas y artículos del caso de María Teresa también permiten percibir un sesgo de género. La prosa poética que distingue la mayoría de los

\footnotetext{
${ }^{26}$ Carlos Monsiváis, «La política del melodrama», Revista N, suplemento cultural del Diario Clarín, 25 de junio de 2005, acceso: 12 de junio de 2020, http://www.panoramadelarte.com.ar/hamal/pdf/la_politica_del_melodrama.pdf

${ }^{27}$ Monsiváis, «La política del melodrama».

${ }^{28}$ Monsiváis, «El melodrama..., 107.

${ }^{29}$ Ibíd.

${ }^{30}$ Carlos Monsiváis, «La política del melodrama». ESPIGA' (1) (1) (-) 
escritos $^{31}$, presumiblemente de autores masculinos, contrasta con el artículo de una mujer, Julia Marta, en el que de manera breve y clara explica la emergencia de mujeres criminales por su situación de inferioridad en una sociedad que les niega derechos. Para Marta, las mujeres delinquen desde su posición de género, por lo que la solución debe ser de tipo social: la educación femenina como instrumento para el reconocimiento de sus derechos y la transformación en una sociedad igualitaria ${ }^{32}$.

No es que los escritores hombres escriban de forma melodramática con la intención consciente de mantener la inequidad de género. Escriben así porque es la estrategia narrativa que se ha impuesto en la nota roja, y aunque es obvio su afán moralizador, no perciben de manera totalmente clara $^{33}$ que lo hacen desde una posición de autoridad que les permite definir cómo deben ser las mujeres y, en general, las relaciones de género. Marta, en cambio, escribe desde su experiencia e identifica claramente la situación de subordinación en que se encuentran las mujeres en una sociedad patriarcal. La intencionalidad en la autoría masculina es normativa y, en el caso de Julia Marta, de denuncia.

$\mathrm{Al}$ respecto, Gayatri Chakravorty Spivak planteó la problemática de la representación de la subalternidad en los relatos históricos ${ }^{34}$. Refiriéndose a la situación colonial en la que Occidente impuso su explicación y narración de la realidad como normativa, señala que en el caso de las mujeres hay una subordinación múltiple, pues además de las subordinaciones económicas, políticas o raciales, están las de género. Dado que la construcción ideológica del género establece el dominio de lo masculino, la historia es escrita desde una perspectiva androcéntrica que no solo omite la voz femenina, sino que además narra la «realidad femenina» desde la perspectiva masculina y establece su normativa. Así, las mujeres carecen de un lugar de enunciación propio en las sociedades patriarcales.

Esto queda ejemplificado en el caso de María Teresa. Lo que sabemos de ella no es lo que ella dice, sino lo que los hombres reporteros dicen acerca de ella. No es su realidad sino la imagen que los periódicos han construido de ella. La narración que se descubre allí no es la de María Teresa como individuo o la del crimen cometido, sino la de las relaciones de género que construyen imágenes de femineidad y masculinidad. Esto es muy claro en la narración del último día del juicio de María Teresa, donde los elementos simbólicos de la femineidad configuran el melodrama de la mujer delincuente.

María Teresa se había enamorado del general Moisés Vidal y, temiendo que su familia no lo aceptara, se casó con él a escondidas. Ya casados, fueron a vivir a casa de los padres de María Teresa. Fue allí, donde el 25 de agosto de 1929, María Teresa leyó en un periódico que Moisés había sido acusado por su primera esposa, María Teresa

\footnotetext{
${ }^{31}$ Algunos ejemplos desde los títulos mismos: «Miss México relató ante su juez, anegada en llanto, la honda tragedia», «Jóvenes de 14 años encenegadas en el fango de todos los vicios», El Nacional Revolucionario, 27 de agosto de 1929; «Conmovida bajo el peso de su pena», Excélsior, 29 de noviembre de 1929.

32 Julia Marta, «Los crímenes femeniles», El Nacional Revolucionario, 3 de diciembre de 1929.

${ }^{33}$ Porque perciben como naturales las identidades genéricas y no como relaciones de poder.

${ }^{34}$ Gayatri Chakravorty Spivak, «¿Puede hablar el subalterno?», Revista Colombiana de Antropología 39, (2003), 297-364. 
Herrejón, de bigamia. María Teresa confrontó a Moisés sobre la veracidad de la noticia, Moisés intentó restar importancia al asunto; María Teresa tomó la pistola de Moisés, que estaba a la vista, sobre una mesa, y amenazó con suicidarse. Moisés intentó quitarle la pistola y, en el forcejeo, recibió los seis disparos de la pistola.

Como ya se mencionó, El Nacional Revolucionario privilegió en sus textos las palabras del Fiscal, licenciado Luis G. Corona, quien clasificó a María Teresa en el grupo de Cleopatra, Mesalina, Lucrecia Borgia y Salomé, invocadas como símbolos de las malas mujeres. La referencia histórica genera la ilusión que las transgresiones femeninas siempre han existido y, por lo tanto, su contrario, el modelo femenino que se transgrede también es eterno. De esta manera, el género se legitima como ahistórico.

También ejemplificó las diferencias entre dos tipos de mujeres con María Teresa y la primera esposa de Moisés. A esta última la considera una mujer buena, sin deseos de venganza, de las que lloran «sin haber pecado» ${ }^{35}$.

María Teresa no era madre, a diferencia de la primera esposa de Moisés, quien declaró nunca haber pensado en matarlo porque era el padre de sus hijas, además, tampoco pensó en suicidarse ${ }^{36}$ porque tenía que cuidar a sus hijas. Así, plantea que la maternidad hacía buenas a las mujeres porque sus propios intereses y emociones eran desplazados por los de las hijas e hijos que debían cuidar.

Para el licenciado Corona, la mujer a través de la historia «ha debido sonreír al dolor», la mujer siempre «se ha nutrido con el dolor», como la Virgen de Galilea, entre otras. Mientras tanto, la que se educa «con el ejemplo malo del cinema y el teatro, la que estudia la posición de una pistola, la que se defiende con gritos y aspavientos» ${ }^{37}$, no se considera una verdadera mujer.

$\mathrm{Al}$ respecto, Joan Scott ha señalado como uno de los elementos que conforman el género en tanto relación primaria de poder, la existencia de símbolos culturalmente disponibles que evocan representaciones múltiples como referentes significativos en las relaciones entre géneros y la construcción de la identidad sexual ${ }^{38}$. La Virgen María es un símbolo recurrente en las llamadas sociedades occidentales y marca un deber ser exageradamente idealizado al que deben aspirar las mujeres, anteponiendo la maternidad a cualquier otro interés y suprimiendo la sexualidad para el goce. Por si fuera poco, el licenciado Corona, durante su argumentación, consideró a la Virgen como un personaje histórico, no mitológico, que hay que imitar, especialmente en la capacidad para soportar el dolor. Su contrario es la mujer que se defiende, como María Teresa, quien ha tomado el mal ejemplo del cinema y el teatro.

\footnotetext{
${ }^{35}$ Arellano Martínez, «María Teresa Landa fue absuelta por el jurado», El Nacional Revolucionario, 1 de diciembre de 1929.

${ }^{36}$ Durante los primeros días de prisión de María Teresa, se especuló que intentaba suicidarse: «María Teresa de Landa relata sollozante cómo dio muerte al hombre que la engañó», Excélsior, 27 de agosto de 1929. «Miss México parece resuelta a morir de hambre», El Nacional Revolucionario, 28 de agosto de 1929.

${ }^{37}$ Arellano Martínez, «María Teresa Landa fue absuelta por el jurado».

${ }^{38}$ Joan W. Scott, «El género: una categoría útil para el análisis histórico», en Género e Historia (México D.F.: FCE/UACM, 2008), 265-302.

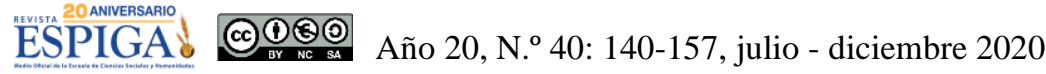


Por su parte, el abogado defensor, José María Lozano, consideró a María Teresa «una víctima del medio social y de la educación que recibió, recalcando la influencia del cine y del jazz en la vida moderna ${ }^{39}$. Desde esta perspectiva, María Teresa no es responsable, lo que implicaría reconocerla como actor histórico, sino la víctima pasiva de los cambios sociales que la han enajenado hasta el grado de cometer un homicidio. En los textos de El Universal se describe a la señora Herrejón como «ponderada, serena, desapasionada. Tiene todas las características de una de esas mujeres excelentes para el hogar, que sólo saben de constantes perdones para el marido calavera ${ }^{40}$. Y después se hace la comparación: «La una revela todo el fuego de un impetuoso temperamento: -es la "civilizada"... -La otra una pasividad, una quietud espiritual enorme: ¡es madre de familia!» ${ }^{41}$.

Lozano resumió: «La señora Herrejón no mató porque no había honor que defender ${ }^{42}$. La señora Herrejón es dulce; hay hijas de por medio ${ }^{43}$, atribuyendo a la diferencia de temperamentos el que la señora Herrejón no hubiera matado al conocer la infidelidad de su esposo, mientras que María Teresa, sí. Y también a los roles sociales: la señora Herrejón es madre. Queda la duda de si era dulce y tenía hijas o si era dulce porque tenía hijas. En cualquier caso, se considera imposible que ella mate porque «hay hijas de por medio».

Por su parte, el licenciado Corona agrega el elemento nacional a la comparación:

(...) la mujer mexicana, todo dulzura, todo amor, todo sacrificio! (...) Pero contra nuestras mujeres se han comenzado a levantar ya los rudos enemigos que combaten su virtud: el frívolo espíritu que las arroja a ir desnudas por las calles, el feminismo que ahoga su femenidad (...) Y principalmente la vanidad, esa que las atormenta cuando ellas consideran el anonimismo en que se hallan y desean romperlo, salir de él, no importa que sea en concursos de bañistas o matando a un hombre. Las oportunidades que les ofrezcan fáciles triunfos, el sentir en las manos el cetro de Reina de la Belleza, y embrujadas por ello no se dan cuenta de que sólo dan el primer paso en los abismos de la perdición. Y todo ante el Moloch del mercantilismo! [sic $]^{44}$.

Ya había advertido que María Teresa no formaba parte del primer tipo, el de «nuestras madres, de nuestras hijas, de nuestras esposas ${ }^{45}$, con lo que establecía una otredad.

Por lo que recomienda que María Teresa vaya a prisión y utilice esos años en cautiverio para meditar y «depure su alma y adquiera las perfecciones morales que la

\footnotetext{
${ }^{39}$ Arellano Martínez, «María Teresa Landa fue absuelta por el jurado».

40 «Un hermano del General Vidal asegura que a éste [sic.] no lo mató su segunda esposa la "Señorita México"», El Universal, 31 de agosto de 1929.

${ }^{41}$ Carlos G. Villanave, «La viuda de Vidal y Miss México, careadas», El Universal, 1 de diciembre de 1929.

${ }^{42}$ Al ser la primera esposa se le consideraba la esposa legítima. María Teresa de Landa, en cambio, era considerada adúltera.

${ }^{43}$ Carlos G. Villanave, «El sensacional jurado de "Miss México"», El Universal, 1 de diciembre de 1929.

44 Ibíd.

45 Ibíd.
}

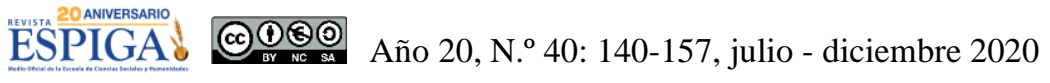


hagan ser una verdadera mujer ${ }^{46}$. Es decir, al no ser parte de lo que el fiscal considera «mujer mexicana», es conceptualizada en una situación inferior como mujer que no logra cumplir con las expectativas de género de la mujer mexicana. La mujer mexicana es entonces presentada como una abstracción homogeneizante: no importan la edad, la clase social o económica, la escolaridad o la trayectoria de vida individual; de haber pertenecido al tipo de «mujer mexicana», María Teresa hubiera sacrificado su amor y pedido a Moisés que regresara con sus hijas, por no tener ellas la culpa de los errores del padre, según el licenciado Corona.

El licenciado Lozano también expuso su propia versión histórica de la mujer, señalando que en el Decamerón de Bocaccio, a las campanadas de la muerte por la peste, «respondían los gritos dyonisíacos [sic], como un símbolo de vida ${ }^{47}$. Durante la Edad Media «la mujer está en silencio o en el gineceo, porque en ella se continúa el misterio inefable de la vida» ${ }^{48}$. Es decir, para Lozano el papel histórico de la mujer es el de la procreación.

Después, Lozano habló de los derechos de las mujeres, derechos que los hombres no reconocen: «Nosotros llevamos tantos siglos de gobernar, de estrujar y de humillar a la mujer, y cuando la vemos salir sangrienta de la tienda de Holofernes o de la Redacción del "Fígaro" de París, no le concedemos el derecho de la pasión. La pasión es para el hombre. A la mujer solo le concedemos el derecho de llorar» ${ }^{49}$. Se podría interpretar entonces que reconocer que María Teresa había actuado motivada por la pasión, era concederle un derecho.

El licenciado Lozano también expuso su punto de vista sobre la educación femenina: «¿Cómo se educa a la mujer moderna? Empieza la educación en la escuela, donde ahora priva la educación promiscua: desde los seis años empieza a tener contacto con los hombres. Más tarde tiene como únicos espectáculos el cine, donde desfilan todas las escenas de lujuria, y el "jazz" que traduce toda la concupiscencia africana» ${ }^{50}$.

La educación gratuita y laica establecida en la Constitución había sido una de las principales demandas durante el movimiento revolucionario, además de que sería la base para formar una nueva ciudadanía. Sin embargo, seguía habiendo grandes reticencias para extender la educación a las mujeres. El discurso de Lozano ejemplifica uno de los principales prejuicios: niños y niñas u hombres y mujeres compartiendo un mismo espacio daban pie a la promiscuidad. La sexualidad latente convertía la educación en una influencia nociva para las mujeres. Si se agregaba el cine, mostrando escenas de lujuria, y las cadencias sensuales del jazz, se obtenía una mujer delincuente. Tal parecería que el conocimiento de la sexualidad sería la peor influencia que podía tener una mujer.

${ }^{46}$ Ibíd.

${ }^{47}$ Ibíd.

${ }^{48}$ Ibíd.

${ }^{49}$ Ibíd.

50 «María Teresa de Landa fue absuelta y triunfó el Príncipe de la Palabra», Excélsior, 1 de diciembre de 1929.

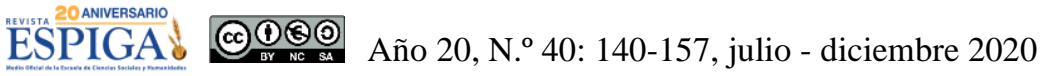




\section{Conclusiones}

Un Jurado Popular exoneró a María Teresa. Al respecto, hay que considerar que era común que los hombres que asesinaban a sus parejas sentimentales, hubiese vínculo legal o no, eran exonerados bajo el argumento del crimen pasional, pues estar sujeto a emociones incontrolables implicaba la incapacidad de razonar y, por lo tanto, se establecía la inexistencia de un móvil.

En el caso de María Teresa no se argumentó el crimen pasional, pues como señaló el abogado defensor, la pasión era el derecho de los hombres, mientras que el de las mujeres era llorar. Si extrapolamos este criterio al campo de la sexualidad, vemos que a los hombres se les atribuía una pasión sexual incontrolable, por lo que correspondía a las mujeres responsabilizarse de la sexualidad. Así, en los textos periodísticos, no se menciona la bigamia de Moisés como delito: se trata de «calaveradas» que una buena mujer debe perdonar.

Entonces, si cada periódico construyó una imagen diferente de María Teresa como individuo, para lo cual seleccionaron la información que dieron a conocer sobre María Teresa y su juicio, al final estas diferentes versiones acabaron complementándose para crear una representación única de los roles de género, en lo que Michel Foucault definió como dispositivo de sexualidad: el conjunto de discursos sobre el sexo y las tecnologías de normalización de las identidades sexuales $^{51}$.

En ese mismo sentido, la mezcla de elementos míticos, literarios e históricos para definir a las mujeres en los argumentos del juicio muestra la intertextualidad que construye la representación de una esencia femenina ahistórica y, por lo tanto, corruptible, pero no modificable.

Según las notas periodísticas, las mujeres buenas aceptan el dolor como protagonistas del melodrama femenino: asumen el sufrimiento como una fatalidad que trasciende a través de anteponer los intereses y deseos ajenos a los propios; además se liga el tema de la nacionalidad: las buenas mujeres son mexicanas.

En cambio, las mujeres que se defienden, que asumen sus intereses y deseos, son delincuentes; lo son porque no saben purificarse por medio del dolor, de allí que la cárcel sea necesaria para obligarlas a meditar en el deber ser femenino. Además, son malas mexicanas porque han preferido la civilización y la modernidad a la tradición. La autora de este artículo considera que la necesidad de ligar el deber ser femenino con la nacionalidad responde a un momento de activa participación femenina en torno a exigir el reconocimiento de sus derechos: el que las mujeres mexicanas de la época se asumieran como actores sociales y políticos, se combatía presentándolas como mujeres fallidas, en tanto que criticaban el papel de la tradición y aspiraban a una modernidad que consideraban incluyente.

De allí, que la construcción de las imágenes de María Teresa como individuo se construyeran a partir de la dicotomía mujer buena / mujer mala, pues las mujeres eran representadas como ejemplos de la condición femenina y no como individuos

${ }^{51}$ Michel Foucault, Historia de la sexualidad 1: la voluntad de saber (México D.F.: Siglo XXI, 1977), 93-159.

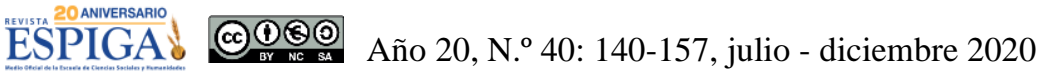


con diversas situaciones de vida (como la clase social, el nivel de educación, experiencias, etcétera). Por lo tanto, enjuiciar a María Teresa implicaba moralizar a todas las mujeres como género, es esa prédica moral la que difunden los textos periodísticos.

En ese mismo sentido, que los tres periódicos hicieran patente sus diferentes posiciones políticas, pero coincidieran en un deber ser femenino único, crea la ilusión de que el género está por encima o es ajeno al ámbito político. Además, la coincidencia desde diferentes lugares de enunciación en el modelo de femineidad genera una intertextualidad que le concede un alto valor como «verdad» aceptada ${ }^{52}$. La femineidad se presenta entonces como una esencia biológica, centrada en lo que Marcela Lagarde ha definido como el cautiverio de madresposa: la condición de opresión genérica en el que las mujeres establecen una dependencia vital hacia los otros a través de la maternidad, la filialidad y la conyugalidad ${ }^{53}$.

Pero es necesario también advertir que la construcción melodramática del deber ser femenino es campo fértil para la violencia contra las mujeres, bajo el supuesto de que se les debe castigar por no cumplir el ideal del rol de género establecido $\mathrm{y}$, a la vez, negarles el derecho a defenderse.

\section{Formato de citación según APA}

García-Blanco, E. (2020). Género y melodrama en la nota roja: el caso de María Teresa de Landa (México, 1929). Revista Espiga, 20 (40), páginas 140-157

\section{Formato de citación según Chicago-Deusto}

García-Blanco, Eleatriz. «Género y melodrama en la nota roja: el caso de María Teresa de Landa (México, 1929)». Revista Espiga 20, n. ${ }^{\circ} 40$ (julio-diciembre, 2020): páginas 140-157

\section{Fuentes consultadas}

Arellano Martínez. «María Teresa Landa fue absuelta por el jurado». El Nacional Revolucionario, 1 de diciembre de 1929.

Australia, Gerardo. «De Miss México a Viuda Negra: el crimen pasional de María Teresa de Landa en 1929». Relatos e Historias en México, n. ${ }^{\circ}$ 57, 2013, 2633.

\footnotetext{
${ }^{52}$ Marie-Christine Leps, Apprehending the Criminal (North Caroline: Duke University Press, 1992), 3-13.

${ }^{53}$ Marcela Lagarde, Los cautiverios de las mujeres: madresposas, monjas, putas, presas y locas (México D.F.: UNAM, 1997).

ESPIGA- @(1) (1) Año 20, N.o 40: 140-157, julio - diciembre 2020 
Buffington, Robert M. Criminales y ciudadanos en el México moderno. México D.F.: Siglo XXI, 2001.

Burkholder de la Rosa, Arno. «El periódico que llegó a la vida nacional. Los primeros años del diario Excélsior (1916-1932)». Historia MexicanaLVIII, n. ${ }^{\circ} 4$ (1999), 1389-1390.

Covo, Jacqueline. «La prensa en la historiografía mexicana: problemas y perspectivas». Historia Mexicana, n. ${ }^{\circ} 3$ (1993), 689-710.

El Nacional Revolucionario. «Jóvenes de 14 años encenegadas en el fango de todos los vicios». El Nacional Revolucionario, 27 de agosto de 1929.

--- «Los padres son culpables de la degeneración». El Nacional Revolucionario, 9 de agosto de 1929.

--- «Miss México parece resuelta a morir de hambre». El Nacional Revolucionario, 28 de agosto de 1929.

--- «Miss México relató ante su juez, anegada en llanto, la honda tragedia». El Nacional Revolucionario, 27 de agosto de 1929.

El Universal. «Un hermano del General Vidal asegura que a éste [sic.] no lo mató su segunda esposa la “Señorita México”». El Universal, 31 de agosto de 1929.

Excélsior. «Conmovida bajo el peso de su pena». Excélsior, 29 de noviembre de 1929.

--- «Expectación al llegar el juez y el defensor». Excélsior, 29 de noviembre de 1929.

--- «María Teresa de Landa relata sollozante cómo dio muerte al hombre que la engañó», Excélsior, 27 de agosto de 1929.

--- «María Teresa de Landa fue absuelta y triunfó el Príncipe de la Palabra», Excélsior, 1 de diciembre de 1929.

Foucault, Michel. Historia de la sexualidad 1: la voluntad de saber. México D.F.: Siglo XXI, 1977.

Illouz, Eva. El consumo de la utopía romántica: el amor y las contradicciones culturales del capitalismo. Buenos Aires/Madrid: Katz, 2009.

Instituto Nacional de Estudios Históricos de las Revoluciones de México, «85 aniversario de la fundación de El Nacional», INEHRM. Acceso el 12 de junio del 2020.

http://www.inehrm.gob.mx/es/inehrm/85_Aniversario_de_la_fundacion_de _el_Nacional

Lagarde, Marcela. Los cautiverios de las mujeres: madresposas, monjas, putas, presas y locas. México D.F.: UNAM, 1997.

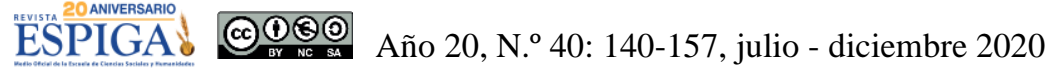


Marta, Julia. «Los crímenes femeniles». El Nacional Revolucionario, 3 de diciembre de 1929.

Leps, Marie-Christine. Apprehending the Criminal. North Caroline: Duke University Press, 1992.

Monsiváis, Carlos. «El melodrama: "No te vayas mi amor, que es inmoral llorar a solas"». En Narraciones anacrónicas de la modernidad: melodrama e intermedialidad en América Latina. Santiago de Chile: Editorial Cuarto Propio, 2002.

--- «La política del melodrama», Revista Ñ, suplemento cultural del Diario Clarín, 25 de junio de 2005. Acceso el 12 de junio de 2020. http://www.panoramadelarte.com.ar/hamal/pdf/la_politica_del_melodrama .pdf

Muñiz, Elsa. Cuerpo, representación y poder. México: UAM/Grupo Editorial Miguel Ángel Porrúa, 2002.

Ruiz Castañeda, María del Carmen. «La prensa de la Revolución (1910-1917) », en El periodismo en México: 500 años de historia. México: Edamex/Club Primera Plana, 1998, 263-286.

Scott, Joan W. «El género: una categoría útil para el análisis histórico», Género e Historia. México D.F.: FCE/UACM, 2008, 265-302.

Spivak, Gayatri Chakravorty. «¿Puede hablar el subalterno?», Revista Colombiana de Antropología, 39, (2003), 297-364.

Villanave, Carlos G. «El sensacional jurado de "Miss México"». El Universal, 1 de diciembre de 1929.

--- «La viuda de Vidal y Miss México, careadas». El Universal, 1 de diciembre de 1929. 